\title{
DIMENSI METRIK PENGHAPUSAN SATU SIMPUL GRAF DUAL ANTIPRISMA
}

\author{
FENNY FITRIANI \\ Program Studi S1 Statistika, \\ Fakultas Sains dan Teknologi, Universitas PGRI Adi Buana, \\ Kampus UNIPA Surabaya, Indonesia, \\ email : fenny_f@unipasby.ac.id
}

Diterima 12 Juni $2021 \quad$ Direvisi 22 Juni $2021 \quad$ Dipublikasikan 26 Juli 2021

\begin{abstract}
Abstrak. Graf dual antiprisma $A_{m, n}^{\prime}$ merupakan graf yang terbentuk dari graf antiprisma $A_{n}$. Selanjutnya dilakukan penghapusan simpul dari graf dual tersebut. Dapat diperoleh dimensi metrik dari graf dual antiprisma serta graf yang terbentuk dari penghapusan satu simpul pada graf dual antiprisma.

Kata Kunci: Dimensi metrik, Graf dual antiprisma, Penghapusan simpul
\end{abstract}

\section{Pendahuluan}

Salah satu yang dipelajari dalam teori graf adalah graf dual. Graf dual merupakan suatu bentuk graf yang terbentuk dari graf lain dengan sifat bahwa sisi-sisinya tidak saling berpotongan. Contoh graf yang dapat dijadikan dasar untuk membentuk graf dual adalah graf antiprisma. Dalam [1] diperoleh bahwa graf dual yang terbentuk dari graf antiprisma memiliki $m(3 n 2)$ simpul dan $2 m(n 1)+2$ sisi. Dari graf dual yang terbentuk tersebut, dilakukan kajian lanjutan mengenai dimensi metrik dari graf. Dimensi metrik adalah minimum kardinalitas dari himpunan pembeda dari graf. Beberapa penelitian telah dilakukan untuk mencari dimensi metrik dari graf. Graf-graf yang digunakan pada penelitian mengenai dimensi metrik ini antara lain graf buku ganda [2], graf antiprisma [3], graf sun [3], graf barbel $B_{2 n}$ pada [4], dan famili graf tangga pada [5]. Dari [6] diperoleh bahwa jika dilakukan penghapusan satu simpul pada suatu graf maka nilai dari dimensi metrik graf yang dihasilkan dari penghapusan satu simpul tersebut akan berbeda dengan nilai dimensi metrik graf awal. Penelitian yang menyangkut mengenai penghapusan simpul ini dapat ditemukan pada [7]. Akan tetapi penelitian tersebut tidak membahas mengenai dimensi metrik dari penghapusan simpul suatu graf, melainkan membahas mengenai pelabelan jumlah eksklusif pada graf hairy-cycle. Berdasarkan hal tersebut, maka dalam artikel ini akan dijabarkan mengenai dimensi metrik yang didapatkan apabila dilakukan penghapusan simpul pada graf dual antiprisma. 


\section{Landasan Teori}

\subsection{Graf Dual Antiprisma}

Definisi 2.1. [1] Graf $A_{m, n}^{\prime}$ merupakan graf dual yang terbentuk dari graf antiprisma $A_{m}^{n}$ dimana region dari graf antiprisma merupakan simpul dari graf dual antiprisma, dan sisi yang menghubungkan dua simpul dari graf dual antiprisma terbentuk jika region dari graf antiprisma yang direpresentasikan oleh simpul saling dipisahkan secara langsung dengan suatu sisi.

Himpunan simpul dan himpunan sisi yang dimiliki oleh graf $A_{m, n}^{\prime}$ adalah

$$
\begin{aligned}
V\left(A_{m, n}^{\prime}\right)= & \left\{u_{i, j} \mid 1 \leq i \leq m, 1 \leq j \leq 2 n-2\right\} \cup\left\{u_{0}, u_{n}\right\}, \\
E\left(A_{m, n}^{\prime}\right)= & \left\{u_{i, j}, u_{i, j+1} \mid 1 \leq i \leq m, 1 \leq j \leq 2 n-2\right\} \cup\left\{u_{i, 2 j} u_{i+1,2 j-1} \mid 1 \leq i \leq m, 1 \leq j<n\right\} \\
& \cup\left\{u_{0} u_{i, 1} \mid 1 \leq i \leq m\right\} \cup\left\{u_{m, 2 i} u_{1,2 i-1} \mid 1 \leq i<n\right\} \cup\left\{u_{n} u_{i, 2 n-2} \mid 1 \leq i \leq m\right\},
\end{aligned}
$$

\subsection{Graf Jahangir $J_{2 n}$}

Pada [8] dijelaskan bahwa graf Jahangir $J_{2 n}$ merupakan suatu graf yang terbentuk dari graf $C_{n}$ dengan $n \geq 2$ dengan penambahan satu simpul yang bertetangga dengan $n$ simpul genap pada graf $C_{n}$.

Teorema 2.2. [8] Jika $n \geq 4$, maka dimensi metrik dari $J_{2 n}$ adalah

$$
\operatorname{dim}\left(J_{2 n}\right)=\left\lfloor\frac{2 n}{3}\right\rfloor
$$

\section{Pembahasan}

Pada bagian ini diberikan teorema-teorema yang didapatkan untuk dimensi metrik dari graf dual antiprisma dengan penghapusan satu simpul pada graf dual yang terbentuk.

Teorema 3.1. Jika graf $A_{m, 2}^{\prime}-u_{2}$ adalah graf yang terbentuk dari penghapusan simpul $u_{2}$ pada graf $A_{m, 2}^{\prime}$ untuk $m \geq 1$, maka dimensi metrik dari $A_{m, 2}^{\prime}-u_{2}$ adalah

$$
\operatorname{dim}\left(A_{m, 2}^{\prime}-u_{2}\right)=\left\lfloor\frac{2 n}{3}\right\rfloor
$$

Bukti. Karena $A_{m, 2}^{\prime}-u_{2} \cong J_{2 m}$ maka dari [8] diperoleh bahwa

$$
\operatorname{dim}\left(A_{m, 2}^{\prime}-u_{2}\right)=\operatorname{dim}\left(J_{2 m}\right)=\left\lfloor\frac{2 n}{3}\right\rfloor .
$$

Teorema 3.2. Jika graf $A_{3, n}^{\prime}-u_{n}$ adalah graf yang terbentuk dari penghapusan simpul $u_{n}$ pada graf $A_{3, n}^{\prime}$ untuk $n \geq 1$, maka dimensi metrik dari $A_{3, n}^{\prime}-u_{n}$ adalah

$$
\operatorname{dim}\left(A_{3, n}^{\prime}-u_{n}\right)=2\left\lfloor\frac{2 n}{3}\right\rfloor+2 .
$$

Bukti. Untuk membuktikan $\operatorname{dim}\left(A_{3, n}^{\prime}-u_{n}\right)=2\left\lfloor\frac{2 n}{3}\right\rfloor+2$, akan ditentukan batas atas dan batas bawah dari $\operatorname{dim}\left(A_{3, n}^{\prime}-u_{n}\right)$. Perhatikan dua kasus berikut. 


\section{Batas atas.}

Untuk pembuktian $\operatorname{dim}\left(A_{3, n}^{\prime}-u_{n}\right) \leq 2\left\lfloor\frac{2 n}{3}\right\rfloor+2$, definisikan suatu himpunan pembeda $W_{1}=\left\{u_{1,1}, u_{2,1}, u_{1,2 n 3}, u_{2,2 n 3}\right\} \cup\left\{u_{1,6 i 1}, u_{2,6 i 1} \mid 1 \leq i<\left\lfloor\frac{n}{3}\right\rfloor\right.$ untuk $\left.\left\lfloor\frac{n}{3}\right\rfloor>1\right\}$.

Jika $n \bmod 3 \equiv 0$ atau $n \bmod 3 \equiv 1$, maka diperoleh bahwa setiap simpul mempunyai representasi yang berbeda terhadap $W_{1}$. Tetapi jika $n \bmod 3 \equiv$ 2, maka diperoleh bahwa terdapat simpul-simpul di lingkaran terluar graf memiliki representasi yang sama terhadap $W_{1}$. Selanjutnya, konstruksi $W_{2}=$ $\left\{u_{1,3}, u_{2,3}, u_{1,2 n 5}, u_{2,2 n 5}\right\} \cup\left\{u_{1,6 i+1}, u_{2,6 i+1} \mid 1 \leq i<\frac{n-2}{3}\right.$, untuk $\left.\frac{n-2}{3}>1\right\}$ jika $n$ $\bmod 3 \equiv 2$. Diperoleh bahwa representasi tiap simpul berbeda terhadap himpunan $W_{2}$ untuk $n \bmod 3 \equiv 2$. Dari uraian tersebut, diperoleh bahwa

$$
\operatorname{dim}\left(A_{3, n}^{\prime}-u_{n}\right) \leq 2\left\lfloor\frac{2 n}{3}\right\rfloor+2
$$

\section{Batas bawah.}

Misalkan $W$ adalah himpunan pembeda dengan $|W|=2\left\lfloor\frac{2 n}{3}\right\rfloor+1$. Perhatikan beberapa kasus berikut.

(i) Jika himpunan $W$ dibentuk dengan mengambil satu simpul dari $2\left\lfloor\frac{2 n}{3}\right\rfloor+1$ lingkaran yang berbeda pada graf dual, maka akan terdapat titik dengan representasi yang sama terhadap himpunan $W$.

(ii) Jika terdapat dua sampai tiga simpul dari himpunan $W$ berada pada lingkaran pertama, maka terdapat simpul-simpul dengan representasi yang sama terhadap himpunan $W$.

Dari uraian didapatkan kardinalitas dari $W$ adalah $|W| \geq 2\left\lfloor\frac{2 n}{3}\right\rfloor+2$. Sehingga,

$$
\operatorname{dim}\left(A_{3, n}^{\prime}-u_{n}\right) \geq 2\left\lfloor\frac{2 n}{3}\right\rfloor+2 .
$$

Teorema 3.3. Jika graf $A_{4, n}^{\prime}-u_{n}$ adalah graf yang terbentuk dari penghapusan simpul $u_{n}$ pada graf $A_{4, n}^{\prime}$ untuk $n \geq 1$, maka dimensi metrik dari $A_{4, n}^{\prime}-u_{n}$ adalah

$$
\operatorname{dim}\left(A_{4, n}^{\prime}-u_{n}\right)=\left\lceil\frac{n}{2}\right\rceil+1
$$

Bukti. Untuk membuktikan $\operatorname{dim}\left(A_{4, n}^{\prime}-u_{n}\right)=\left\lceil\frac{n}{2}\right\rceil+1$, akan ditentukan batas atas dan batas bawah dari $\operatorname{dim}\left(A_{4, n}^{\prime}-u_{n}\right)$. Perhatikan dua kasus berikut.

Batas atas.

Untuk pembuktian $\operatorname{dim}\left(A_{4, n}^{\prime}-u_{n}\right) \leq\left\lceil\frac{n}{2}\right\rceil+1$, definisikan suatu himpunan pembeda $W_{3}=\left\{u_{1,2}, u_{4,2}\right\} \cup\left\{u_{4,6(2 i 1)} \mid 1 \leq i<\left\lfloor\frac{n+2}{6}\right\rfloor\right\} \cup\left\{u_{3,2 n-3} \mid n \bmod 3 \equiv 0, n\right.$ ganjil $\}$ $\cup\left\{u_{1,2 n-3} \mid n \bmod 3 \equiv 1,2, n\right.$ ganjil $\} \cup\left\{u_{2,6 i+4} \mid 1 \leq i \leq k, i\right.$ ganjil $\} \cup\left\{u_{2,6 i+2} \mid 1 \leq\right.$ $i \leq k, i$ genap $\}$. Untuk $n \bmod 6 \equiv 0,1$ nilai $k=2\left\lfloor\frac{\bar{n}}{6}\right\rfloor-1$, sementara untuk $n$ $\bmod 6 \equiv a$, dengan $a \in\{2,3,4,5\}$, nilai $k=2\left\lfloor\frac{n}{6}\right\rfloor$. Diperoleh bahwa $\left|W_{3}\right|=\left\lceil\frac{n}{2}\right\rceil+1$, dengan representasi setiap simpul berbeda. Diperoleh

$$
\operatorname{dim}\left(A_{4, n}^{\prime}-u_{n}\right) \leq\left\lceil\frac{n}{2}\right\rceil+1
$$


Batas bawah.

Misalkan $W$ adalah himpunan pembeda dengan $|W|=\left\lceil\frac{n}{2}\right\rceil$. Perhatikan beberapa kasus berikut.

(i) Jika himpunan $W$ dibentuk dengan mengambil satu simpul dari $\left\lceil\frac{n}{2}\right\rceil$ lingkaran yang berbeda pada graf dual, maka akan terdapat titik dengan representasi yang sama terhadap himpunan $W$.

(ii) Jika terdapat sebanyak $\left\lceil\frac{n}{2}\right\rceil \leq 4$ simpul dari himpunan $W$ berada pada lingkaran pertama, maka terdapat simpul-simpul dengan representasi yang sama terhadap himpunan $W$.

Dari uraian didapatkan kardinalitas dari $W$ adalah $|W| \geq\left\lceil\frac{n}{2}\right\rceil+1$. Sehingga,

$$
\operatorname{dim}\left(A_{4, n}^{\prime}-u_{n}\right) \geq\left\lceil\frac{n}{2}\right\rceil+1
$$

Teorema 3.4. Jika graf $A_{m, n}^{\prime}-u_{n}$ adalah graf yang terbentuk dari penghapusan simpul $u_{n}$ pada graf $A_{m, n}^{\prime}$ untuk $n \geq m, m \geq 5$, maka dimensi metrik dari $A_{m, n}^{\prime}-u_{n}$ adalah

$$
\operatorname{dim}\left(A_{m, n}^{\prime}-u_{n}\right)=n-1
$$

Bukti. Untuk membuktikan $\operatorname{dim}\left(A_{m, n}^{\prime}-u_{n}\right)=n-1$, akan ditentukan batas atas dan batas bawah dari $\operatorname{dim}\left(A_{m, n}^{\prime}-u_{n}\right)$. Perhatikan dua kasus berikut.

Batas atas.

Untuk pembuktian $\operatorname{dim}\left(A_{m, n}^{\prime}-u_{n}\right) \leq n-1$, definisikan suatu himpunan pembeda $W_{4}=\left\{u_{i, 2} \mid 1 \leq i<m-2\right\} \cup\left\{u_{1,2(m+i)-2} \mid 0 \leq i \leq n-m\right\}$. Diperoleh bahwa $\left|W_{4}\right|=n-1$, dengan representasi setiap simpul berbeda. Diperoleh

$$
\operatorname{dim}\left(A_{m, n}^{\prime}-u_{n}\right) \leq n-1
$$

\section{Batas bawah.}

Misalkan $W$ adalah himpunan pembeda dengan $|W|=n-2$. Dengan mengambil $m-3$ simpul dari lingkaran terdalam, dan $n-m+1$ simpul pada lingkaran luar, maka akan terdapat simpul dengan representasi yang sama, yaitu $u_{i, 1}$ dengan $u_{j, 1}$, dan $u_{k, 2}$ dengan $u_{l, 2}$. Jadi haruslah

$$
\operatorname{dim}\left(A_{m, n}^{\prime}-u_{n}\right) \geq n-1
$$

Berikut diberikan satu contoh penentuan dimensi metrik graf dual antiprisma dengan menghapus salah satu simpul dari graf yang terbentuk.

Contoh 3.5. Pada Gambar 1 diberikan graf $A_{8,2}^{\prime}-u_{2}$.

Dari Teorema 3.1 diperoleh dimensi metrik dari graf dual $A_{8,2}^{\prime}-u_{2}, \operatorname{dim}\left(A_{8,2}^{\prime}\right)=$ 5. Misalkan himpunan $W=\left\{u_{1,1}, u_{2,2}, u_{3,2}, u_{6,1}, u_{6,2}\right\}$. Diperoleh representasi se- 


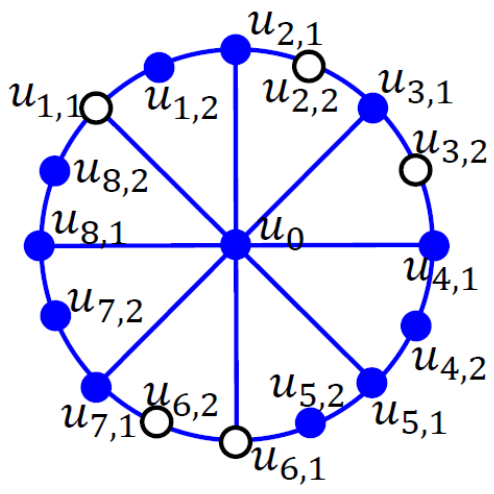

Gambar 1. Graf $A_{8,2}^{\prime}-u_{2}$

tiap simpul $u \in V\left(A_{8,2}^{\prime}-u_{2}\right)$ terhadap $W$ adalah sebagai berikut:

$$
\begin{aligned}
r\left(u_{0} \mid W\right) & =(1,2,2,1,2), r\left(u_{1,1} \mid W\right)=(0,3,3,2,3), r\left(u_{1,2} \mid W\right)=(1,2,4,3,4), \\
r\left(u_{2,1} \mid W\right) & =(2,1,3,2,3), r\left(u_{2,2} \mid W\right)=(3,0,2,3,4), r\left(u_{3,1} \mid W\right)=(2,1,1,2,3), \\
r\left(u_{3,2} \mid W\right) & =(3,2,0,3,4), r\left(u_{4,1} \mid W\right)=(2,3,1,2,3), r\left(u_{4,2} \mid W\right)=(3,4,2,3,4), \\
r\left(u_{5,1} \mid W\right) & =(2,3,3,2,2), r\left(u_{5,2} \mid W\right)=(3,4,4,1,2), r\left(u_{6,1} \mid W\right)=(2,3,3,0,1), \\
r\left(u_{6,2} \mid W\right) & =(3,4,4,1,0), r\left(u_{7,1} \mid W\right)=(2,3,3,2,1), r\left(u_{7,2} \mid W\right)=(3,4,4,3,2), \\
r\left(u_{8,1} \mid W\right) & =(2,3,3,2,3), r\left(u_{8,2} \mid W\right)=(1,4,4,3,4)
\end{aligned}
$$

Dari hasil representasi tersebut terbukti bahwa $\operatorname{dim}\left(A_{8,2}^{\prime}-u_{2}\right)=5$.

\section{Kesimpulan}

Dimensi metrik graf dual antiprisma $A_{m, n}^{\prime}$ dengan penghapusan satu simpul didapatkan pada empat keadaan. Keadaan pertama, jika simpul $u_{2}$ dihapus pada graf $A_{m, 2}^{\prime}$ dengan $m \geq 1$, maka $\operatorname{dim}\left(A_{m, 2}^{\prime}-u_{2}\right)=\left\lfloor\frac{2 m}{3}\right\rfloor$. Keadaan kedua, jika simpul $u_{n}$ dihapus pada graf $A_{3, n}^{\prime}$ dengan $n \geq 1$, maka dimensi metrik dari graf yang didapat adalah $\operatorname{dim}\left(A_{3, n}^{\prime}-u_{n}\right)=2\left\lfloor\frac{n}{3}\right\rfloor+2$. Keadaan ketiga jika simpul $u_{n}$ dihapus pada graf $A_{4, n}^{\prime}$ dengan $n \geq 1$, maka dimensi metrik dari graf yang didapat adalah $\operatorname{dim}\left(A_{4, n}^{\prime}-u_{n}\right)=\left\lceil\frac{n}{2}\right\rceil+1$. Keadaan keempat jika simpul $u_{n}$ dihapus pada graf $A_{m, n}^{\prime}$ dengan $n \geq m$ dan $m \geq 5$, maka dimensi metrik dari graf yang didapat adalah $\operatorname{dim}\left(A_{m, n}^{\prime}-u_{n}\right)=n 1$.

\section{Ucapan Terima kasih}

Terima kasih kepada Dr. Darmaji S.Si., MT atas arahan dan saran yang diberikan tentang topik yang dijabarkan. 
384 Fenny Fitriani

\section{Daftar Pustaka}

[1] Fitriani, Fenny, 2021, Graf Dual Antiprisma dan Dimensi Metriknya, E-Jurnal Matematika, $10: 611$

[2] Ilmayasinta, Nur, 2019, Dimensi Metrik pada Graf Buku Ganda, Dimensi Metrik pada Graf Buku Ganda, Jurnal Pendidikan Matematika dan Matematika, I : 21 27

[3] Khoiriah, S.,Kusmayadi, T.A., 2018, Dimensi Metrik Lokal Pada Graf Antiprisma Dan Graf Sun, Journal of Mathematics and Mathematics Education, 8 : 915

[4] A. Murtaza, A. Gohar, A. Usman, Rahim M.T. 2012. On Cycle Related Graphs with Constant Metric Dimension. Journal of Discrete Mathematics 2: 2123

[5] Saifudin, I., 2016, Dimensi Metrik dan Dimensi Partisi dari Famili Graf Tangga, JUSTINDO, Jurnal Sistem dan Teknologi Informasi Indonesia, 1 : 105112

[6] Fitriani, F., 2019, Dimensi Metrik Penghapusan Satu Simpul Graf Dual Prisma, MUST: Journal of Mathematics Education, Science and Technology, 4 : 108113

[7] Addinnitya, A., 2012, Pelabelan Jumlah Eksklusif pada Graf Matahari, Graf Korona, dan Graf Hairycycle dengan Banyak Simpul Lingkaran Genap, Skripsi di Universitas Indonesia, tidak diterbitkan

[8] Tomescu, I., Javaid, I., 2007, On the metric dimension of Jahangir graph, Bull. Math. Soc. Sci. Math. Roumanie, 50 : 371376 